\title{
COVID-19 pandemic hospital management experience in Turkey
}

\section{Experiencia de manejo pandémico COVID-19 en un hospital de Turquía}

\author{
Okhan Akdur* \\ Emergency Medicine Department, Faculty of Medicine, University of Canakkale Onsekiz Mart, Canakkale, Turkey
}

COVID-19, the disease caused by the SARS-CoV-2 coronavirus, has affected approximately nine million people around the world. ${ }^{1}$ All health institutions have had to review their capacities and systems to fight this disease. Hospital management has had to rethink its parameters regarding personnel, equipment and number of beds. ${ }^{2}$ Many hospitals have had to undergo restructurings in their combat against this disease.

In Turkey, the Ministry of Health and the government have made very important and adequate decisions with the help of an advisory council, the Scientific Council, made up of academics and experts.

It is of the utmost importance to transmit the practices and experiences acquired in hospital management during the pandemic process.

\section{Suggestions}

Hospital management should take into consideration the following indications regarding the restructuring of hospitals during the pandemic period.

- Hospitals of each region or city should be structured to provide services exclusively to pandemic-related patients from the beginning, i.e., they should become "pandemic hospitals".

- Hospital managers should create a committee made up of professionals from the relevant scientific areas, which has to be in charge of making decisions and carrying out the necessary preparations. This committee should be fully authorized for decision-making.

- Hospitals should be immediately integrated into the national health system. Information regarding patients and hospital data should be available at the national health system.

- Training and information should be provided to all hospital personnel regarding the use of personal protective equipment and the disease, a process that should be recorded.

- Measures should be taken to ensure that all patient data can be integrated into a local or national health record system, and teams should be assigned to control the flow of data.

- The responsibility for assessing, controlling and treating patients with COVID-19 should rest with experts in infectious diseases, cardiopulmonary diseases and intensive care, as well as with hospital emergency departments. Continuous communication with the responsible personnel should be maintained.

- Provincial and regional directors should hold regular meetings with the hospital director in order to evaluate the process.

- Decisions should be notified in writing to all health personnel working at the units.

- Healthcare personnel requests and complaints should be assessed with calm. Acting with transparency and always encouraging the staff is advocated.

- Circulation through hospital areas should not be allowed without wearing masks, and this measure should include administrative personnel.

- A real-time information exchange system should be established through a hospital information management system regarding the number of

0016-3813/0 2020 Academia Nacional de Medicina de México, A.C. Published by Permanyer. This is an open access license (http://creativecommons.org/licenses/by-nc-nd/4.0/). 
admitted COVID-19 cases, number of active hospital workers, available beds and status of devices (number of available respirators, etc.). Consideration of the above by hospital managers will ensure a satisfactory management of the pandemic.

\section{References}

1. World Health Organization [Internet]. Switzerland: Coronavirus disease 2019 (COVID-19), situation report-160: data as received by WHO from national authorities by 10:00 CEST, 28 June 2020; 2020.

2. Garg M, Wray CM. Hospital medicine management in the time of COVID-19: preparing for a sprint and a marathon. J Hosp Med. 2020;15: 305-307. 